\title{
12. Harmonization of similar instruments
}

\author{
Rachel Slater
}

\subsection{INTRODUCTION}

We have been writing about harmonization of social protection in general, and of social transfers in particular, for at least two decades. Among the earliest references to the issue is found in Norton et al. $(2001,13)$ where social protection is noted to be 'fragmented and poorly coordinated, making balanced judgements about priorities and the appropriate role for public policy difficult'. Donor agencies followed soon after with, for example, UNICEF suggesting in 2008 that 'There is an urgent need to reduce fragmentation and increase harmonization in (national) social protection programme support and delivery'. Increasing harmonization is, in turn, a key step towards achieving integrated social protection systems - those that address social and economic vulnerabilities; provide a comprehensive set of interventions; go beyond risk management intervention and safety nets to address structural vulnerabilities; facilitate multi-sectoral coordination; coordinate with supply-side investments (e.g. delivery of basic services); and situate social protection within wider social and economic policies (UNICEF 2012).

More recently, the International Labour Organization argued that 'In many countries, social protection programmes... struggle with limited coverage, inadequate benefit levels, fragmentation and weak institutionalization' $(2019,11)$ and calls to address fragmentation were made at the Ministerial Forum at the United Nations Commission for Social Development's 57th Session in 2019 (United Nations 2019). Social protection publications - whether they are strategies, policies, evaluations or research reports - are replete with these concerns about the fragmentation and lack of coherence of programmes and systems. Some programmes even include harmonization in their names (for example the Harmonized Social Cash Transfer Programme in Zimbabwe).

However, while the symptoms have been widely reported over many years - patchy coverage, inconsistent transfer levels, limited linkages between programmes or inefficient and unreliable delivery - there is rather less detailed diagnosis of what the problem is and even fewer articulations of solutions.

This chapter seeks to address these gaps in problem diagnosis and identification of solutions. It begins by providing a framework for harmonization, then unpicks the problem of fragmentation and explains why it arises. It then uses real-world examples from low- and middle-income countries to show how it can be tackled. Although when people talk about harmonization they tend to be discussing harmonization between social transfers and social insurance, and between social protection and wider programmes, or sectors and systems such as health, education and rural development, in this chapter the focus is narrower. Here the emphasis is on harmonization between individual social transfer schemes or within social transfer systems. There are good reasons for doing this.

First, harmonizing across a range of social transfer programmes helps to enhance coverage and reduce gaps. In turn, this can contribute to more inclusive social protection where spe- 
cific groups or individuals are not left out. Second, it allows us to make efficiency gains in programmes - for example by avoiding the duplication of administrative infrastructure and by integrating beneficiary information systems to identify where some households receive multiple benefits while others receive nothing. Third, it renders more visible the similarities and differences between programmes and forces policy-makers and practitioners to provide a consistent logic as to who gets what and why. Fourth, in turn, this can make social transfers more equitable - by aligning benefit levels and the logic applied to setting them.

\subsection{FRAMING FRAGMENTATION AND HARMONIZATION}

This section draws on concepts of effectiveness, efficiency and equity, to provide an analytical framing of harmonization to guide the subsequent analysis in the chapter.

'Fragmentation' is rarely explicitly defined but has become a catch-all term referring to a whole range of design, coverage, financial, targeting and information challenges in social protection programmes and systems. As a corollary, the term 'harmonization' provides a similar, but unsubstantiated, catch-all for the solution. A good starting point for unpacking harmonization is what we are seeking to achieve. In this chapter, the primary goal of harmonization is assumed to be effective social protection, that is, social protection that meets the needs of poor and vulnerable people.

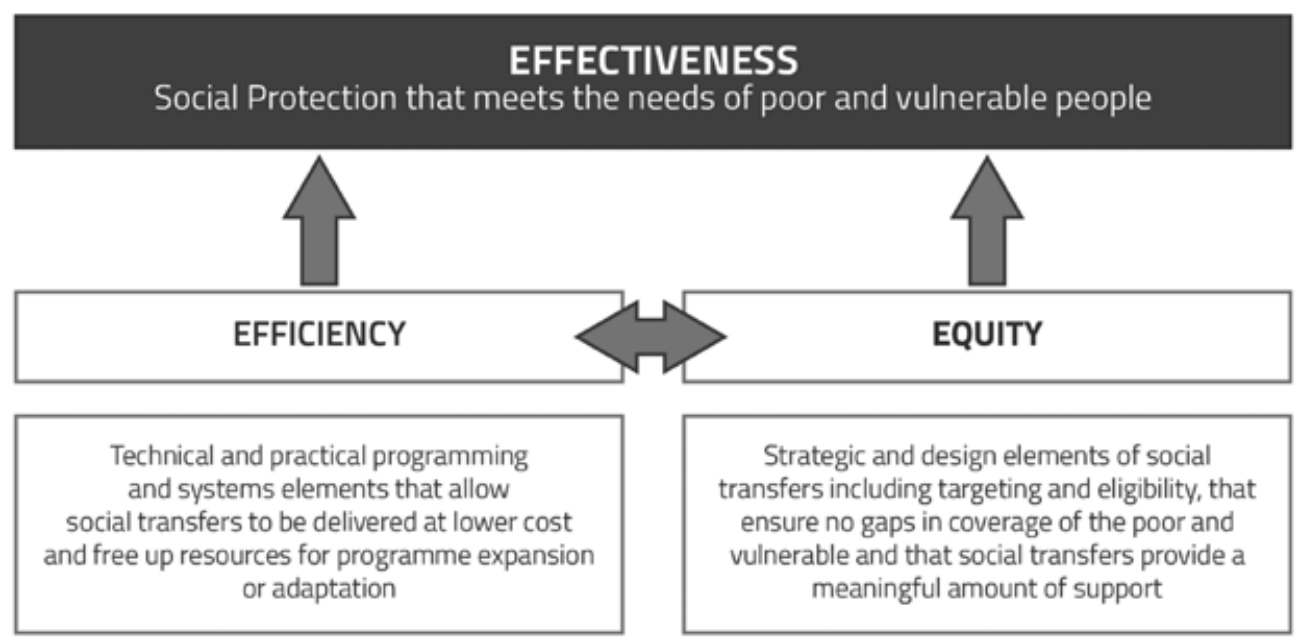

Source: Author's own illustration.

Figure 12.1 Goals of harmonization-efficiency, equity and effectiveness

To achieve effectiveness, two important intermediate outcomes of harmonization are efficiency and equity (Figure 12.1). The distinction allows a focus on practical and technical actions, such as alignment of programme features, single registries or electronic payment systems (efficiency) and more strategic elements, such as choice of transfer modality, or which 
people or groups are eligible to receive transfers, through which entitlements to social transfer coverage can be realized (equity). In the former, we are ensuring that things work well (and addressing the second and third reasons for harmonizing highlighted above); in the latter that no one is left out and different groups of people get what they specifically need (addressing the first and fourth reasons for harmonization). Actions to achieve efficiency and equity both contribute to effectiveness, but they are also mutually reinforcing. For example, savings made through administrative efficiency can create the fiscal space to increase coverage of groups hitherto left out of social transfers. In the other direction, the increases in coverage that result from more inclusive or universal programming create efficiencies through economies of scale and reduced transaction costs.

Tackling both efficiency and equity is important. While there are many explicit examples of attempts to improve technical and practical programming elements of social transfers by international agencies, lessons from the European Commission (2011) in relation to Europe suggest that working towards efficiency (for example by tighter targeting, reducing fraud, etc.) alone is not enough. 'This... may very well alleviate, or at least mitigate, extreme poverty at the very bottom of the income distribution but the impact on relative poverty and income inequality is less straightforward' $(2011,6)$.

\subsection{FRAGMENTATION CHALLENGES IN SOCIAL TRANSFER SCHEMES}

In this section, key fragmentation challenges are described. Overall, the implications of fragmentation are significant, particularly in terms of cost. White et al. (2013) explored the Government of Bangladesh's efforts to strengthen the coordination, targeting and coverage of the country's array of programmes. They found that, together, existing programmes reached less than a third of poor families and reduced the poverty gap by only 10 per cent, but cost 2.4 per cent of gross domestic product (GDP) (including as much as 0.6 per cent of GDP for the state-funded civil service pension, not always included in the definition of social transfers). They concluded that for the same cost it would be possible to provide a universal child grant and a universal social pension, reaching 94 per cent of poor families and reducing the poverty gap by 35 per cent. So addressing fragmentation and having greater harmonization can free up resources to achieve far more with social protection. Doing so requires a more detailed look at the nature of fragmentation challenges across policy, institutional and administrative domains.

Key fragmentation challenges include the following:

\subsubsection{Too Many Programmes}

Concerns about the problem of a proliferation of many small programmes are common in the social protection literature. In Bangladesh, for example, programmes run into the hundreds bringing challenges of replication and alignment. The World Bank reported 99 government safety net programmes in 2013 (plus many more run by non-governmental organizations (NGOs)) and 140 in 2016. In 2020, the Social Security Policy Support Programme reported there were 118 social protection programmes, many of them social transfers, across 25 distinct ministries or divisions (World Bank 2013, 2016; Government of Bangladesh 2018). Having 
multiple smaller programmes means missing out on economies of scale in targeting, registration, payments and monitoring systems and thus increasing the cost of delivery.

\subsubsection{Replication and Overlaps}

Replication occurs when there are multiple programmes all tackling one particular problem and tends to result in another equally urgent problem being ignored. Similarly, there are major concerns (expressed from both efficiency and equity points of view) about situations in which some beneficiaries receive multiple sources of support, because different programmes target the same people, while others qualify for no support whatsoever. There is limited evidence that the extent of overlapping beneficiaries warrants the level of concern (see for example evidence on limited overlaps of social transfers at household level in Nepal (Slater et al. 2018)). However, there is limited data available - especially household survey data that can identify when households receive more than one programme. The Atlas of Social Protection (ASPIRE) database is rather better at measuring gaps than duplication. ASPIRE data can identify where households receive both social assistance (i.e. transfers) and social insurance, but does not yet distil how many households receive more than one social transfer programme because 'Indicators do not count for overlap among program types (people receiving more than one program)' (World Bank 2018, 35). Getting better evidence is important for identifying overlapping coverage - especially where there are many small non-government transfer programmes run by NGOs and donor agencies - and is key for addressing duplication.

\subsubsection{Lack of Coverage/Uneven Coverage}

There are a number of ways that fragmentation results in a lack of coverage. A good example is related to social transfers seeking to improve food security: food transfers and education stipends delivered in schools predominantly focus on primary-aged children attending school and miss those that are under five, in secondary school or who have dropped out. This is despite strong evidence of both the importance of programmes in meeting nutrition needs during the first 1000 days of life and an increasing recognition of the importance (but chronic under-resourcing) of adolescents, especially girls. In many parts of the world, support for people with disability or who are unemployed lags behind transfers for other groups. The United Nations Department of Economic and Social Affairs (UN DESA), drawing on the International Labour Organization (2018a), finds that, in Africa for example, unemployment cover is at 6 per cent compared to coverage of 23 per cent for older people (pensions) and 16 per cent for children. For transfers for people with severe disability there is a paucity of data on Sub-Saharan Africa, with records of coverage available for only a handful of countries (Burkina Faso 0.1 per cent, Cameroon 0.1 per cent, Mali 0.6 per cent, Mozambique 0.6 per cent and South Africa 64.3 per cent), suggesting very low coverage except in South Africa (ILO 2019). Three elements that can explain these coverage gaps are discussed in more detail in the next section: global funding opportunities; political preoccupations; and administrative simplicity. 


\subsubsection{Varying Benefit Levels}

Another challenge is the situation of similar programmes paying rather different transfer levels - without a clear rationale or formula for doing so. In Nepal, senior citizens receive 2000 Nepali rupees (NPR) each month, poor/vulnerable households with children under five receive NPR400, widows and single women NPR1000 and people with disability between NPR300 and 2000 per month. In Kenya, variations in payment levels in the main social transfer programmes has led to substantial efforts to better align the programme benefits discussed below (Republic of Kenya 2017). While it is clear that different groups will have different needs, with the implication that some will require greater transfers than others, the range of values seen at present implies that setting transfer levels is frequently based less on a clear methodology incorporating a robust assessment of need and more on what is politically palatable. This in turn can create further inequity where some groups are seen as more deserving than others.

\subsubsection{Limited Integration of Administrative Systems}

In particular, where social transfer programmes are delivered by different ministries or departments of government, there can be substantial dislocation of administrative systems. Different programmes may use different targeting approaches, payment pathways (mobile or e-banking payments versus physical cash distribution), grievance mechanisms and might hold separate lists of beneficiaries in each organization. This can result in both inefficiencies (for example the use of multiple mobile money agents at a greater unit cost) and inequities (for example overlaps and gaps in beneficiary coverage). For the poorest and most vulnerable households, these multiple systems can be both confusing and time-consuming to navigate.

\subsubsection{Lack of Consideration of Operational Elements Beyond the Transfers Themselves}

It is widely acknowledged that beyond the costs and administration of transfers themselves, there are many wider elements in the administration of social transfers. Some programmes are substantially more administration-intensive than others, for example, conditional cash transfer programmes that require information and monitoring systems to verify compliance with conditions. Harmonizing administration systems can provide important routes to efficiency. This is the case within social transfers but it is also important to look beyond social transfers themselves to other sectors. In South Africa, UNICEF $(2008,11)$ note that 'the main constraints to expanding the social security system relate more to delivery capacity than to budgetary constraints'. They argue that services linked to social transfers are fragmented, that institutional coherence is lacking and there are not enough social workers, social auxiliary workers and community development practitioners. For example, foster care grants are provided to nearly half a million households each but the real financial constraint is in the funding of social workers organizing court orders, regular supervision and returning to court to reapply after two years. The challenges in South Africa are as much about harmonization beyond social transfers as within them, but recognizing wider administrative demands of social transfers remains important for harmonization within. 


\subsection{WHAT CAUSES FRAGMENTATION?}

Having identified key fragmentation challenges in the previous section, the focus here is on the drivers, structural or otherwise, of fragmentation.

\subsubsection{Low Capacity in Ministries leading Social Transfer Programmes and Systems}

In many countries, ministries leading on social transfers are weak and the lack of institutional capacity contributes to fragmentation:

Social protection is often caught in a vicious cycle - the inherent institutional weaknesses can reduce the programming effectiveness (leading to leakage and corruption) and promote fragmentation. This in turn reduces the profile, coverage, and resources for the responsible ministries and for social protection activities. Though capacity of social protection led ministries (usually ministries of gender, or labour and social affairs) varies immensely between regions, they consistently exhibit a low profile relative to other parts of Government. (UNICEF 2008, 18)

It is also common for social transfers to be implemented by a number of different ministries. As a result, tackling institutional capacity constraints in social transfers is a key part of the harmonization agenda.

\subsubsection{Fragmentation as an Inherent Feature of Donor-Supported Systems in Low- and Middle-Income Countries}

Fragmentation (and subsequent harmonization) can be interpreted as part of the natural evolution of social transfer systems in situations where there is heavy international engagement. Limited government engagement in low-income countries and erratic funding of fledgling programmes results in short-term, projectized approaches by governments. This is compounded where NGOs fill the government programme vacuum with a plethora of programmes each with limited coverage. The need to persuade governments that social protection is affordable and financially sustainable leads to a proliferation of 'proof-of-concept' pilot programmes, and donor agencies tending to support actions that align with their in-house definitions and frameworks and their off-the-shelf instruments.

\subsubsection{Fragmentation Driven by the Focus on Rapid-Onset Shocks in Low- and Middle-Income Countries}

While in richer countries the focus of social transfer programmes is lifecycle-related shocks and stresses, in low- and middle-income countries programmes have often emerged in response to climate and environment-related shocks, such as floods and drought. In these situations, both the magnitude and nature of vulnerabilities can change quickly - for example, when conflict or a climate-related disaster triggers displacement - and existing programmes may prove inadequate at tackling these emerging or expanding vulnerabilities and new and different responses are put in place that may lack alignment with existing programmes. 


\subsubsection{Political Drivers of Fragmentation}

Fragmentation can also indicate underlying structural problems with the design, coordination and delivery of transfer programmes that are inherently political. At a national level the influence of political economy can be strong and lead to uneven or skewed coverage. Governments often choose the programmes that provide the path of least resistance. That might mean doing programmes that are technically easy, or providing support that is less controversial. In Nepal, for example, social transfer programmes have emerged not primarily based on comprehensive analysis of vulnerabilities and needs but based on which are 'administratively relatively simple to implement' (particularly categorical-targeted programmes), populist and appropriate within an 'unstable and highly competitive political environment' (Sijapati 2017; Jones 2012, 252). In the worst cases the political expediency leads to distinct patterns of coverage with some communities ignored (UN DESA 2018a). For example, Hossain (2011) finds that, for some social transfers, while over 97 per cent of Adivasi households in Barind, Bangladesh, are technically eligible, less than 3 per cent receive benefits, and argues that this results from a combination of lack of information about programmes and overt discrimination.

\subsubsection{Fragmentation as a Side Effect of Decentralized Governance Systems}

Fragmentation can be symptomatic of situations where federal, state and other programmes operate simultaneously. Asher and Vora (2018), for example, highlight the bewildering array of social protection programmes and instruments in India. They find that the federal structure, among other features, leads to a diffusion of responsibilities for the design, implementation and evaluation of the programmes between the union government and the states that poses 'considerable challenges for policy coherence, and organisational coordination' $(2018,71)$.

\subsubsection{The Politics of Global Funding}

This can also result in fragmentation and can set the logic(s) of programming along multiple specific pathways. In Sub-Saharan Africa especially, the dominance in a number of countries of social protection for 'grannies and orphans' owes much to the availability of funding for responding to the HIV/AIDS pandemic and a subsequent growth of support to skipped-generation households. Evidence on the differential impacts of the HIV/AIDS pandemic were also critical. Gaps in coverage can reflect a lack of knowledge or capacity to deal with complexity. UNICEF $(2008,19)$ suggests that the nature of vulnerability as complex and multi-faceted results in fragmented programming with both governments and donors favouring funding social protection for one specific group over others (e.g. retrenched civil servants, orphans and vulnerable children), hindering efforts to build systems.

\subsection{FROM FRAGMENTATION TO HARMONIZATION: WHAT CAN BE DONE?}

Addressing both the root causes and the symptoms of fragmentation, and making all elements of policy and design, and institutional arrangements and delivery more harmonized across social transfer programmes can result in more effective social protection systems. In 
this section some existing experiences are presented, structured around whether they focus on harmonization of (1) policy and legal frameworks for social protection; (2) institutional arrangements and coordination mechanisms; and (3) programme delivery.

\subsubsection{Strategies, Policies and Legal Frameworks}

At a strategic level, policies, laws and frameworks are a key foundation for harmonization of social transfers. Articulating a clear approach to social protection and transfers is key. Countries that have anchored their social transfers within the social protection floor or that have recognized the importance of social transfer provision across the lifecycle are able to better identify and tackle gaps in coverage (UNECLAC 2015). An example is Bangladesh which has shifted from a 'poor relief' approach to a more comprehensive lifecycle approach which recognizes that individuals face different risks and vulnerabilities at different stages in life, and seeks to design social transfers to address risks at each stage. 'Integrating different programs in one overall system can help to expose gaps in coverage over the life cycle' (UN DESA 2018a). In Myanmar, there is a progression towards establishing a clear policy framework for social transfers. In 2016, the government began to implement a National Social Protection Strategy Plan that sought to address social assistance 'for the majority of the population outside the formal sector for the first time in a systematic manner, moving beyond the few fragmented social transfers in place earlier' (Koehler and Rabi 2017, 367).

Policy frameworks are also critical for achieving efficiency gains that in turn underpin equity gains. In 2013, the World Bank noted that commitments to address targeting and leakage errors in programmes might not be shared by all government practitioners in the 12 ministries that implemented Bangladesh's largest safety net programme. The development of the National Social Protection Strategy was used as a key mitigating measure to ensure a coordinated response to targeting and leakage by creating greater awareness and common understanding across agencies (World Bank 2013).

Articulating a policy framework only takes us so far. Anchoring social protection in national laws is also important and can further encourage the consolidation of multiple schemes into a single, more coherent framework. Examples from Africa are assessed in UNDP (2019), for example. UN DESA (2018a) also notes the importance of a clear legal framework in fostering efficient administration systems, notably where this helps to establish clear lines of responsibility and mechanisms for coordination. Legal frameworks can also take us some of the way towards equity by enshrining rights to social protection. However, in practice, this might not always apply to access to social transfers because laws are rarely explicit about the precise instrument of social protection and may comply with the law using other types of instruments, particularly contributory programmes. One notable exception is India where the Mahatma Gandhi National Employment Guarantee Act 42 of 2005 provides transfers, in return for labour, for 100 days each year. Provision under the Act is a key step to rationalizing India's overabundance of transfer projects.

\subsubsection{Strengthening Coordination and Institutional Arrangements}

At the heart of the harmonization project is institutional coordination and capacity. Social protection policy frameworks often cut across multiple sectors and operationalizing them across 
multiple sectors highlights the importance of coordination and social transfer programmes having clear institutional homes (European Commission 2015d, in UN DESA 2018a).

In a number of countries, the establishment of a social protection or social transfer policy framework - coordinated from a lead ministry but including all those delivering social transfers - is important. In Brazil the Ministry of Social Development was created in 2004 to integrate a range of non-contributory social protection policies for the poor and vulnerable, notably social assistance, conditional cash transfers and transfers for food and nutrition security (Ministry of Social Development 2013). The establishment of a single ministry or agency 'brings a mandate, a budget, clearly defined roles and responsibilities and capacities to implement' (UNDP 2019, 41), but there are other institutional mechanisms to support harmonization including semi-autonomous agencies (South Africa), public bodies under ministries (Kenya) and private management consultancies (Uganda).

For equity - particularly having appropriate social transfer designs for the specific needs of vulnerable groups - it is unwise to automatically assume that a single ministry housing all social transfer programmes is appropriate but it certainly makes a difference when a single ministry is charged with managing coordination. In practice, even under a harmonized system, involvement in social transfers is likely and necessary across a number of ministries. As UN DESA (2018b) notes, 'effectively addressing the needs of individuals who face overlapping disadvantages - such as young migrants, older persons with disabilities or indigenous women - may require programmes that draw on a range of expertise across ministries and other institutions'.

In the case of institutional capacity, international agencies are both part of the problem and potentially part of the solution. International agencies can also have a deleterious impact on harmonization. Developing a consistent approach to institutional strengthening for social protection within and between financial organizations (such as the World Bank and the International Monetary Fund), development organizations (such as the United States Agency for International Development, Foreign, Commonwealth and Development Office (FCDO) and UNICEF) and national governments would be a major contribution to the lessons offered by current social protection systems. There are significant efforts underway for international agencies to work more effectively together. One such route is a 'Three Ones' approach - one national plan, one oversight body, one monitoring and evaluation system. Another is the Social Protection Inter-Agency Cooperation Board process, established in 2012 at the behest of the G20 Development Working Group to convene international and bilateral development partners to better coordinate their policy, advocacy, programming and financial resources in support of nationally owned social protection.

\subsubsection{Improving the 'Plumbing'}

In terms of the efficiency dimension in Figure 12.1, getting delivery systems working effectively is the most important thing. As Asher and Vora (2018) argue, improving social protection's 'plumbing' can lead to better expenditure management and targeting, and by extension to improved outcomes from a given level of expenditure. Other features of social transfer systems that can make substantial contributions to harmonization are described in more detail, including the 'nuts and bolts' of payment systems, single registries, grievance/accountability systems, in Chapters 10, 24, 26, 28 and 33. 
The dominant approach for improving the plumbing is the establishment of social protection information systems (Barca 2017). Efficiency benefits include more streamlined reporting and oversight, the identification and avoidance of duplication and achieving economies of scale in targeting, verification and payment systems. Consolidated information systems can also contribute to greater equity, with greater responsiveness and inclusiveness of interventions and improved transparency and accountability. However, establishing consolidated information systems faces a paradox or catch-22: the very requirements for establishing information systems are precisely those that are lacking in fledgling and fragmented systems. Information systems have high costs and complexities (at least initially), and require high levels of capacity, policy leadership and institutional coordination (Barca 2017).

Another approach to harmonizing is to maximize the benefits of pilot programmes. Social transfer pilots are frequently presented as the pantomime villains of social transfers, the poster child for fragmentation. The Organisation for Economic Co-operation and Development's Development Centre (OECD-DEV 2019, 32) notes that although pilots are part of the problem because they 'pose risks of system fragmentation', they can also be part of the solution by bringing opportunities for productive innovation in social transfers. Drawing on Infante-Villarroel (2016) and Mukherjee et al. (2018), it outlines the mixed results of donor-led pilots:

\begin{abstract}
Starting in 2013, UNICEF supported the implementation of a pilot cash transfer to impoverished pregnant women and children up to the age of five along with behaviour change communication to improve feeding and WASH [water, sanitation and hygiene] practices. The World Bank implemented a near-identical pilot starting in 2014. The duplication represented a less efficient use of aid resources, indicative of the challenge aid fragmentation in Cambodia represents. However, both pilots focused on evidence-building and the resulting corroboration of the independent impact evaluations along with coordinated policy advocacy from the two development partners has led to the implementation of a national cash transfer programme for pregnant women and children.
\end{abstract}

The lesson is that, if pilots are to contribute to harmonization rather than fragmentation, it is important to only use them where they make significant contributions to the development of a more efficient and/or equitable effective system of social transfers and where they are coordinated among donors and government.

Another strategy for achieving buy-in for harmonization, albeit one that is fiercely contested, is results-based funding. In Kenya (Republic of Kenya 2017), five social assistance programmes are being harmonized across two ministries, with harmonization efforts tied to a Program-for-Results lending instrument. A USD250 million loan was provided to the Government of Kenya subject to disbursement-linked indicators including the creation and functioning of grievance mechanisms, as well as streamlining of management information systems and targeting, and progress with a single registry, electronic payments, the timing of payments and wider consolidation of social assistance programmes.

Beyond results-based financing, other shifts in financing systems can yield benefits for harmonized social transfers. Harris (2013) and Garcia and Moore (2012) assess financing systems in Ethiopia finding that, although the government still operates through annual budgets, international agencies are programming with longer time frames and this supports the use of a medium-term expenditure and financing framework for planning purposes. Instead of unscheduled/spontaneous and separate donor contributions to different programmes in different ministries and departments, working through medium-term expenditure and financing frameworks brings together donor contributions and allows timely planning. This in turn 
provides an entry point for better assessment and filling of programming coverage gaps and for shared administrative systems.

Further down the chain, fragmentation and lack of coherence are problems for beneficiaries (or non-beneficiaries) at the local level so robust grievance mechanisms are crucial to ensure that the rights of beneficiaries are respected. 'Making social protection programmes more inclusive requires transparent official avenues for people to challenge their exclusion or denounce discrimination and corruption' (UN DESA 2018b, xxiii). This is central to addressing gaps in cover that are a symptom of exclusion.

\subsection{CONCLUSIONS AND RECOMMENDATIONS}

None of these barriers [to harmonization] are insurmountable. The design and implementation of policies can either keep social protection out of reach for some or, alternatively, give those left behind the opportunity to benefit from them. Whether or not they result in greater social inclusion depends on the specific measures in place and the way in which they are implemented. (UN DESA 2018a, xxi)

This chapter has identified multiple ways in which harmonization can contribute to the effectiveness of social assistance by achieving efficiency and equity outcomes. Although there are paradoxes that challenge progress, a number of recommendations follow from the UN DESA assertion that many of the obstacles to overcoming fragmentation are not insurmountable.

First, it is important to view harmonization as something to be realized progressively by ensuring that social transfers are kept relatively simple in the first instance and delivered effectively (on time, reliably and at meaningful levels), and then incorporate more complex design features over time.

Second, recognizing that fragmentation is as much a political feature as a technical one is key. The use of procedural working groups of multiple stakeholders can go some way to ensuring that the needs of vulnerable groups and the capacities of systems, and not political expediency, drive the transition to more harmonized social transfers.

Third, policy-makers and practitioners need to acknowledge trade-offs, for example the fact that achieving improvements in coverage is not easily achieved alongside delivering higher transfer levels that can make a meaningful difference to people's lives.

Fourth, it is important to also recognize that too few programmes can create inequities. In countries where a single programme dominates the social transfer landscape (the Productive Safety Net Programme in Ethiopia, the Benazir Income Support Programme in Pakistan and the Pantawid Pamilyang Pilipino Programme in the Philippines), the possibilities for meeting varied needs and addressing specific vulnerabilities can be crowded out. The implication is that harmonization efforts that reduce the number of different social transfer programmes too far may create a new problem.

Fifth, we should beware blanket disapproval of ways of working such as allowing social transfers to be delivered by a number of ministries, the engagement of non-government actors and using social transfer pilots. While there are examples of each of these ways of working contributing to fragmentation, that is not always nor automatically the case. Instead, assessing how far delivering in these ways provides opportunities to leverage efficiency and equity gains without contributing to further fragmentation is key.

Finally, it is important to ensure that national governments' priorities are put first, ahead of the institutional mandates, priorities and off-the-shelf instruments of international agencies. 
There is much to do and, if anything, these challenges, and the imperative to harmonize, are growing. The increasing threat of the climate emergency and growing numbers of households displaced by conflict and other crises create new types of vulnerability and increasing caseloads for social transfers. In the case of internally displaced persons and refugees, social transfers are patchy and inconsistently applied by governments and international agencies (UN DESA 2018a). At the time of writing, the COVID-19 pandemic is also creating new sources of vulnerability in low- and middle-income countries. Households are exposed not just to the morbidity and mortality impacts of the virus but also to negative impacts that public health measures designed to reduce the risk of contagion (such as social distancing and curfews) have for livelihoods and household income. Governments and their developing partners are increasingly pivoting social transfer programming - that is notably skewed to rural locations in low-income countries - to urban contexts. Tackling these additional challenges in a coherent way requires programming solutions that are harmonized yet appropriately tailored for specific contexts to ensure equity. In practice that means harmonized systems for targeting and setting payment levels but not automatically using the same targeting criteria and paying the same benefit level for everyone, everywhere.

It also reinforces the fact that tackling the major global development challenges will need harmonization without, too, so not just between social transfers and other elements of social protection, but much more broadly with other sectors such as health, education and agriculture (see also the other chapters in Part III). UN DESA (2018a, 1) suggests that 'deprivations reinforce one another... unequal access to health, education and social protection systems feeds a vicious cycle of disadvantage and exclusion'.

Furthermore, as the Convention on the Elimination of All Forms of Discrimination Against Women (CEDAW 2018, 274) notes, coherence requires the mutual reinforcement of international agendas on disaster risk reduction and climate change adaption with agendas on gender equality, rights to education and information, work and social protection, health and freedom of movement. While social transfers are a small part of these wide and complex agendas, they are an essential part of the 'plumbing', so getting them right is crucial to achieving these wider global goals.

\section{REFERENCES}

Asher, M. and Y. Vora (2018). Social protection system in India: An assessment of the recent initiatives. In M. Asher, F. Zen and A. Dita (eds), Social Protection Goals in East Asia: Strategies and Methods to Generate Fiscal Space. Abingdon: Routledge, 70-97.

Barca, V. (2017). Integrating Data and Information Management for Social Protection: Social Registries and Integrated Beneficiary Registries. Canberra: Commonwealth of Australia, Department of Foreign Affairs and Trade.

CEDAW (2018). General recommendation no. 37 (2018) on the gender-related dimensions of disaster risk reduction in the context of climate change. International Human Rights Law Review 7 (2), 274-307.

European Commission (2011). Improving the efficiency of social protection: Synthesis report. Brussels: European Commission.

Garcia, M. and C. Moore (2012). The Cash Dividend: The Rise of Cash Transfer Programs in Sub-Saharan Africa. Washington, DC: World Bank.

Government of Bangladesh (2018). Social security policy support programme: Project factsheet. Government of Bangladesh, Planning Commission. http://socialprotection.gov.bd/en/2018/11/04/ project-factsheet/ 
Harris, E. (2013). Financing social protection floors: Considerations of fiscal space. International Social Security Review 66, 3-4.

Hossain, Z. (2011). Extreme poor Adivasis and the problem of accessing social safety nets. Working Paper No. 4 (October). Dhaka: Extreme Poverty Research Group and Shiree.

Infante-Villarroel, M. (2016). Cambodia Cash Transfer Pilot Program Process Evaluation. Washington, DC: World Bank.

International Labour Organization (ILO) (2019). World Social Protection Report 2017-2019. Geneva: ILO.

Jones, S. (2012). The politics of social rights: Social protection and free health care in Nepal. Public Management Review Special Issue: The Politics and Governance of Public Services in Developing Countries 14 (2), 239-54.

Koehler, G. and A. Rabi (2017). The case for universal social protection in Myanmar: Options, costs and policy benefits. Global Social Policy 17 (3), 365-74.

Ministry of Social Development (2013). Social policy in Brazil. Brasilia: Ministry of Social Development Presentation.

Mukherjee, A., K. Gupta and T. Chey (2018). Evaluation of the CARD and UNICEF cash transfer pilot project for pregnant women and children in Cambodia: Final report, Volume I. New York: UNICEF.

Norton, A., T. Conway and M. Foster (2001). Social protection concepts and approaches: Implications for policy and practice in international development. ODI Working Paper 143. London: ODI.

OECD-DEV (2019). Lessons from the EU-SPS Programme: Optimising the role of development partners for social protection. EU-SPS Programme. Paris: OECD-DAC.

Republic of Kenya (2017). Kenya social protection sector review 2017. Nairobi: Ministry of Labour and Social Protection.

Sijapati, B. (2017). The quest for achieving universal social protection in Nepal: Challenges and opportunities. Indian Journal of Human Development 11 (1), 17-36.

Slater, R., A. Ghimire and D. Baur (2018). Strengthening Links between Social Protection and Disaster Risk Management for Adaptive Social Protection in Nepal. Washington, DC: World Bank Group.

UN DESA (2018a). Promoting inclusion through social protection: Report on the world social situations 2018. New York: United Nations.

UN DESA (2018b). Social protection for indigenous peoples and ethnic minorities: Overcoming discrimination and geographic isolation. Social Development Brief \#7. New York: United Nations.

UNDP (2019). The State of Social Assistance in Africa. New York: United Nations.

UNECLAC (2015) Towards Universal Social Protection: Latin American Pathways and Policy Tools. Santiago: United Nations Economic Commission for Latin America and the Caribbean.

UNICEF (2008). Expanding social protection for vulnerable children and families: Learning from an institutional perspective. New York: Inter-Agency Task Team on Children on HIV and AIDS Working Group Working Paper, UNICEF.

UNICEF (2012). Social protection strategic framework. New York: UNICEF.

United Nations (2019). Report on the fifty-seventh session (7 February 2018 and 11-21 February 2019). Economic and Social Council Official Records 2019, Supplement No. 6. New York: United Nations Commission for Social Development.

White, P., A. Hodges and M. Greenslade (2013). Measuring and maximising value for money in social protection systems (companion guidance to Measuring and maximising value for money in social transfer programmes). London: DFID.

World Bank (2013). Bangladesh: Safety Net Systems for the Poorest Project. Washington, DC: World Bank.

World Bank (2016). Bangladesh: Promoting More Effective Social Protection and Labor Initiatives. www.worldbank.org/en/results/2016/10/07/promoting-more-effective-social-protection-labor -initiatives

World Bank (2018). The state of social safety nets. Washington, DC: World Bank. 